\title{
STATUS OF THE DOE/SANDIA BLADE MANUFACTURING PROGRAM *4
}

\author{
Thomas D. Ashwill \\ Wind Energy Technology Department \\ Sandia National Laboratories \\ Albuquerque, New Mexico, USA 87185-0708
}

\begin{abstract}
A DOE/Sandia project termed the Blade Manufacturing Program was established at Sandia to develop means of advancing manufacturing processes in ways that lower costs and improve the reliability of turbine blades. Through industry contracts, manufacturers are improving processes such as resin infusion, resin transfer molding, and thermoplastic casting. Testing . and modeling research at universities and national labs are adding to the knowledge of how composite materials perform in substructures and sub-scale blades as a function of their fabrication process.
\end{abstract}

\section{INTRODUCTION}

The cost of utility-grade wind power has steadily dropped in the past several years to values in the range of 4-6 cents per kWh. These gains are largely due to the incorporation of advanced airfoils (increased performance) and tall, lighter turbines (higher average wind speed and reduced turbine weight). To compete with conventional power generation, which is on the order of 2-3 cents per $\mathrm{kWh}$, wind industry manufacturers are searching for additional means of cost reductions. The re-examination of process efficiencies is occurring because labor and material costs are now a higher percentage of the remaining cost of wind power. Blade and rotor manufacturing, in particular, are under consideration for improvements because the rotor cost is typically about $20-25 \%$ of the entire turbine. Breakthroughs in the manufacturing of these components, especially blades, can significantly lower turbine capital costs and the cost of windproduced energy.

This work is suppored by the U.S. Deparment of Energy under Contract DE-ACQ4-04AL85000 and DE-AC36-83CH10093. Sandia is a multiprogram taboratory operaled by Sandia Corporation, a Lockheed Marin company, for the U.S. Deparment of Energy.

$\Psi$ This paper is declared a work of the U.S. Government and is not subjoct to copyright protection in the United States.
In late 1995, a DOE project in turbine manufacturing was established at Sandia to look at ways to improve the manufacturing aspects of turbine production. The emphasis, so far, has been on blade components due to the realization that blades have a significant potential for being more efficiently designed and produced. Through DOE/SNL industry contracts, manufacturers were encouraged to improve their blade building processes. In addition, a small research effort in blade fabrication was started at Sandia Labs. This fabrication research occurs with the development of design-tomanufacture computer tools, testing of composite substructures, and providing support in areas identified in the industry contracts.

The traditional means of making a turbine blade are labor intensive hand lay-up techniques used in boat building and other traditional fiberglass industries. While molds are inexpensive in this process, there are needs for improvements in part consistency, speed of production, and cost. More advanced manufacturing techniques, such as RTM, resin infusion, VARTM, fiber winding, automatic fiber placement, and pultrusion, have crept into the wind industry in various degrees and with varied success. We intend to encourage the incorporation of advanced processes to help lower blade costs, make blades more reliably (quality), and help improve fatigue lives (reduction of stress risers).

These two areas, industry contracting and blade fabrication research, were merged under the heading of the Blade Manufacturing Program. This paper will discuss past and ongoing efforts in this program.

\section{INDUSTRY CONTRACTS}

Advances in blade manufacturing are being made through solicitations such as the recently-completed Blade Manufacturing Project (BMP) and the ongoing Blade Manufacturing Improvements (BMI) project. These solicitations have the same objectives, which are to assist the U.S. industry in the development of . 


\section{DISCLAIMER}

This report was prepared as an account of work sponsored by an agency of the United States Government. Neither the United States Government nor any agency thereof, nor any of their employees, make any warranty, express or implied, or assumes any legal liability or responsibility for the accuracy, completeness, or usefulness of any information, apparatus, product, or process disciosed, or represents that its use would not infringe privately owned rights. Reference herein to any specific commercial product, process, or service by trade name, trademark, manufacturer, or otherwise does not necessarily constitute or imply its endorsement, recommendation, or favoring by the United States Government or any agency thereof. The views and opinions of authors expressed herein do not necessarily state or reflect those of the United States Government or any agency thereof. 


\section{DISCLAIMER}

Portions of this document may be illegible in electronic image products. Images are produced from the best available original document. 
innovative and improved blade manufacturing processes in ways that lower blade costs, improve their quality and reliability and eliminate some of the problems experienced in the field due to poor manufacturing. An additional objective is to broaden the U.S. wind blade manufacturing industry. The BMP resulted in one contract to $A B M / F l o W i n d$, which performed research on wood-epoxy blades. The BMI solicitation resulted in the award of three contracts (TPI, Foam Matrix, and Goldsworthy), each of which make enhancements to different types of fiber-reinforced plastic (FRP) fabrication processes.

\section{$\underline{\mathrm{ABM}}$}

The ABM tasks were: research improvements to the processes and materials used in the manufacture of wood-epoxy blades, conduct tests to qualify any new material or process, and then build and test six blades using the improved processes and materials. In addition, $A B M$ needed to find a replacement material for the mature Douglas fir used in the blades. It has become unacceptable to continue its use due to a limited supply and environmental concerns associated with the use of mature timber.

The parent company, FloWind, declared bankruptcy during this project causing $A B M$ to be unable to complete the full scope of work. ABM did complete much of the research and testing to identify improvements to their manufacturing process.

The baseline blade is that of the AWT-27 turbine, which has blades (approximately $13 \mathrm{~m}$ long) constructed from wood/epoxy laminates with two shells bonded together over an inner vertical shear web. Carbon fiber is incorporated into some of the wood laminates on the tension side, and the shells are sealed on the inner and outer surfaces with a layer of fiberglass. In the most highly loaded layers, the ends of the veneer sheets are scarfed to improve the strength of the joints. In less heavily loaded veneer layers, the sheets are placed endto-end with no pre-treatment to create butt joints.

Reference 1 is a final report that further describes detnils of the project including the results of wood laminate coupon testing. Its findings include the following:

1. Pre-sealing the scarfed joints in the blade shell increased the joint strength to allow for elimination of the carbon reinforcement and results in significant cost savings.

2. Use of heat during the molding process accelerates the epoxy cure enough to allow operation of two shifts per day rather than one and reduces costs significantly.

3. The use of fumed silica as an epoxy extender permits a $20 \%$ reduction in the amount of resin used.

4. Both Loblolly southern pine and new growth Douglas fir were tested as candidates to replace the mature Douglas fir currently used. Neither was found to be acceptable. Loblolly Pine may be a suitable replacement candidate if used with an extended epoxy to reduce epoxy absorption. This was not tested due to resource limitations. An alternative second growth Douglas fir was identified late in the program and may be suitable as well.

5. The quality of the wood laminate is heavily dependent on material characteristics not generally published. There is a big variation in wood strength as a function of tree age and the tendency of wood to absorb epoxy. This dictates thorough testing of any changes in the materials or processes used.

6. Cost reductions were identified in several areas, which when summed up reduce blade costs by $8 \%$ for single shift operations and $14 \%$ for double shift operation.

Almost all blades are currently made from fiberglass materials. It appears the outlook for wood blade production is not promising at this time, however, there does remain a strong interest in wood blades for certain applications.

\section{$\underline{\text { TPI }}$}

This contract involved making manufacturing improvements to the baseline, which is the U.S. Windpower (Kenetech) 56-100 turbine blade. No change was expected in the airfoil design, however a separate NREL contract with TPI's consultant, Dynamic Design, was worked into the project. This made it possible to design a new aerodynamic surface optimized to solve some of the field problems associated with the blade (reduction of pitch loads) and to increase energy capture.

The prototype blade is designated the ERS-100. Several manufacturing and design improvements were incorporated into its development as described in the final report (2). After fabrication the blade was tested at NREL (3) for static strength (Figure 1). A set of blades was flown on a test machine in Solano County and results compared with the baseline design, an LS-1 blade. Figures 2 and 3 show the blade being fabricated

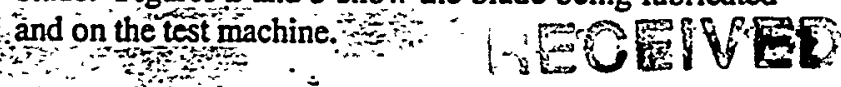

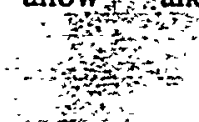

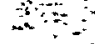
NOV 282000 


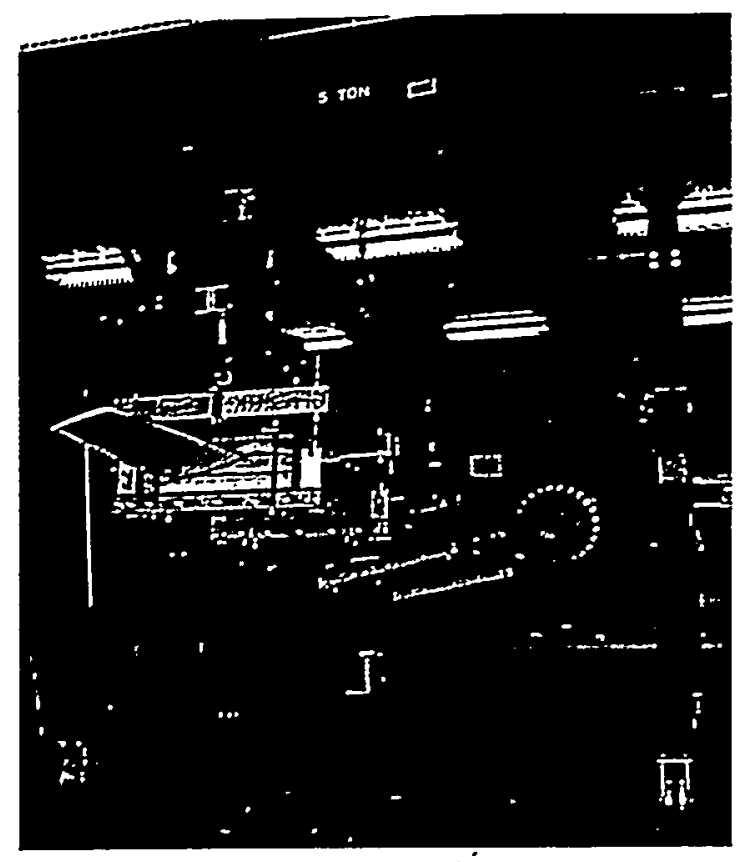

Figure 1. Static testing of TPI blade at NWTC.

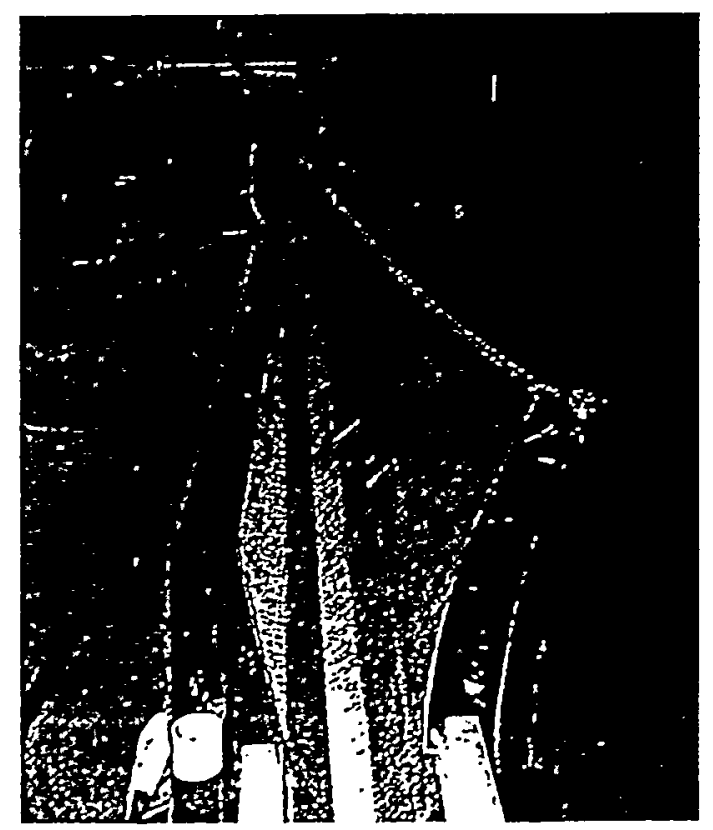

Figure 2. Fabrication of ERS-100 Blade

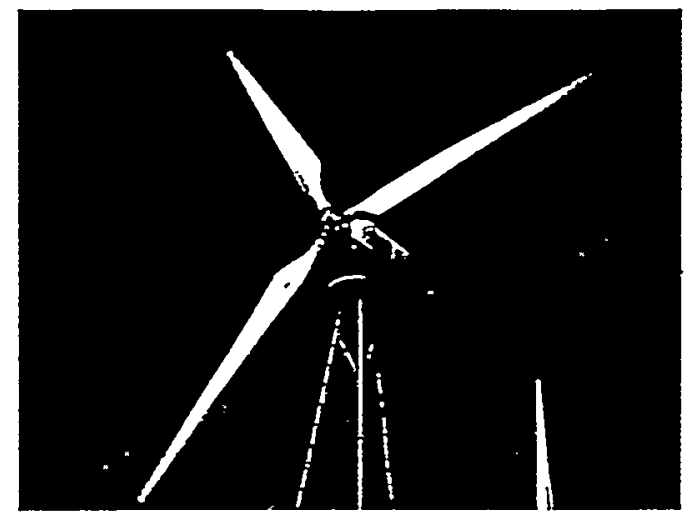

Figure 3. Flight testing of ERS-100.

A summary of the results are as follows:

1. Prototype blades developed under the BMI contract were produced using SCRMPP (Seeman's Composite Resin Infusion Manufacturing Process). Improvements in the manufacturing process under this contract were the use of reusable silicon bags, the use of heated molds, and the elimination of a hoop wrapping step during assembly. Savings of $25-30 \%$ using the improvements with SCRIMP were exhibited over traditional approaches.

2. Blades manufactured with SCRIMP significantly reduce hazardous air emissions over the traditional hand lay-up process.

3. An innovative blade attachment design successfully incorporated bonded studs and met design specifications for static and fatigue strength. Tests indicated that an even more innovative design, direct infusion of the root studs, can also provide sufficient strength. More testing is required to refine design and manufacturing procedures for direct embedment.

4. The static tip deflection of the prototype was less than the baseline and within acceptable margins. Static strength was less than baseline value therefore modest changes to laminate placement will be needed to increase buckling strength.

5. The blade power performance met the design specifications and annual energy is expected to increase at least $10 \%$ at typical sites.

6. Measured root bending loads were similar to the baseline. Further testing is needed to define operating loads in detail. 
An extension to the contract will demonstrate a remote build capability, perform further work on the direct infusion of root studs, and implement recommended modifications to increase the buckling load and refine the shear web placement.

\section{Foam Matrix}

Under this BMI contract Foam Matrix has developed a prototype blade for the $20 \mathrm{~kW}$ Jacobs turbine. Their process uses a closed mold, foam and RTM. The foam serves as a fabrication plug as well as the shear web. (Figure 4 shows the foam core). The fiberglass skin is fabricated with the use of resin transfer molding. The blade planform was optimized with the use of modern airfoils to produce more energy.

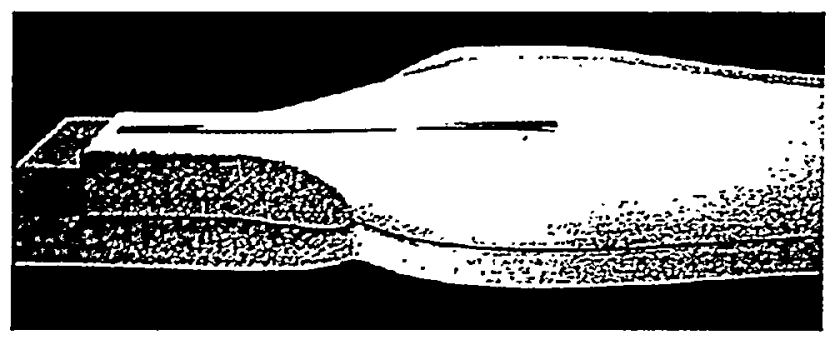

Figure 4. Foam Matrix foam core.

Prototype blades were successful fabricated, and static tests are occurring at NREL as this paper is submitted (fall 2000). Field testing is also currently underway at a test site in Hawaii.

\section{Goldsworthy}

The Goldsworthy contract is innovative as it attempts to design and build a blade using a thermoplastic resin rather than the traditional thermoset resin. The baseline blade is the SERI-8m. Because of cost constraints, only the root half of the blade was built, although the entire blade was designed. The tooling is expandable to allow full blade fabrication at a later date. Manufacturing requires a closed mold (shown in Figure 5), an internal bladder, and an oven. The process consists of wrapping a co-mingled fiberglass/thermoplastic sock around an inner fiberglass shell that houses the spar cap. This structure is put into a closed mold. The entire mold is placed into an oven, the bladder inflated, and the oven temperature brought up to 400 degrees $F$. After a few hours, the mold is removed from the oven and cooled.
The initial mold was to be constructed with an electroforming methodology, however the bids came in higher than expected. Goldsworthy performed an investigation to determine the most efficient and inexpensive methods for making tooling. The candidate methods reviewed were:

\section{Electroforming \\ 2. Casting \\ 3. Stretch Forming \\ 4. Nickel Deposition \\ 5. CNC Machining}

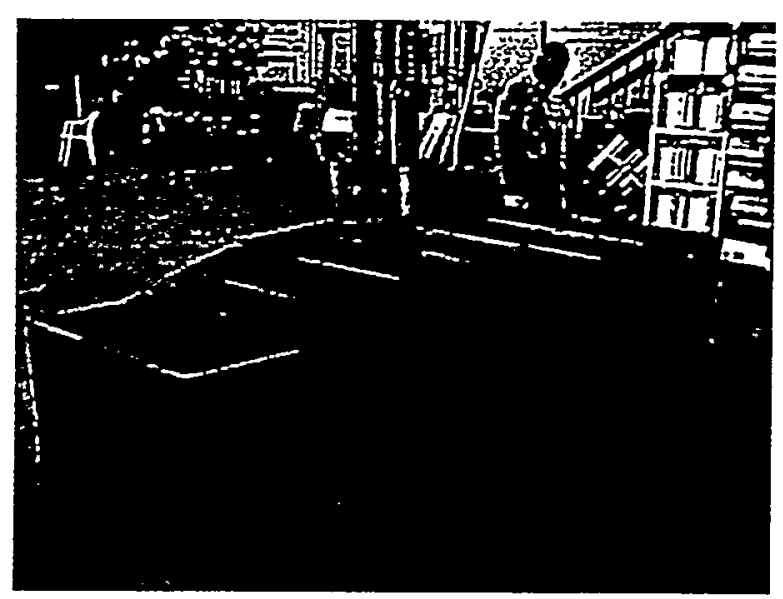

Figure 5. Cast mold for SERI-8m thermoplastic blade.

The casting technique was the least expensive and became the chosen method. The project returned back on budget as the cost of the cast molds were $\$ 100,000$ less than the estimate for molds produced by electroforming.

The innovations are as follows:

1. Thermoplastics rather than thermosets were used as the resin. Thermoplastics can be very inexpensive and give off very little volatiles.

2. An innovative root design was implemented. A steel cylinder is attached to the blade with a reverse taper and a chemical bond developed between the resin and metal during the oven melt. Thus, no bonding is required.

3. A co-mingled "sock" was used as the primary source of blade material. The socks consists of fiberglass and thermoplastic fibers woven together. The thermoplastic material becomes the . 
resin when heated to elevated temperatures. However, significant coupon testing will be necessary to determine the fatigue life.

There have been problems finding a bladder that can exert the appropriate amount of pressure in the high temperature environment. A reinforced bladder is currently under construction.

\section{BLADE FABRICATION RESEARCH}

Work is ongoing in several areas directly related to blade fabrication:

1. Computer tool development

2. Manufacturing process research at Montana State University

3. Component design and testing (Headwaters Composites)

4. Adaptive blades (aeroelastic tailoring)

\section{Manufacturing Analvsis Tool Development}

NuMAD (Numerical Manufacturing and Design) is a software package that allows a user to quickly and easily develop a three-dimensional finite element model (FEM) of a turbine blade. It performs pre-processing and post-processing to the commercial code ANSYS (4), so any computational method (such as structural and modal analyses) can be performed. It is tailored for the creation of turbine blade models and contains databases of airfoil shapes, materials and load cases.

Fully characteristic FEM blade models are difficult to create because of the twist and taper nature of turbine blades and the necessity to create different structural architectures such as spar caps, shear webs, sandwich panels and ply drops. NuMAD incorporates all of these architectures into its modeling capability. Also, the various material constants and fiber lay-ups are part of a library that can be pulled up and automatically inserted into the model. This task is usually onerous for fiberglass materials, which have multi-directional properties.

These features allow a user to quickly create many models, run structural or modal calculations and tailor the output. These characteristics are very useful for parametric or scaling studies. In addition, some manufacturing guidance is available to help the designer create a buildable structure. Such a manufacturing tutorial is being created with input from testing.
Figure 6 shows a typical mesh of a horizontal axis blade with many finite elements, however, it was created using NuMAD in a very short time. Developments have proceeded to the point that an early version is being used by several wind turbine companies. See References 5,6,7 for more details on NuMAD.

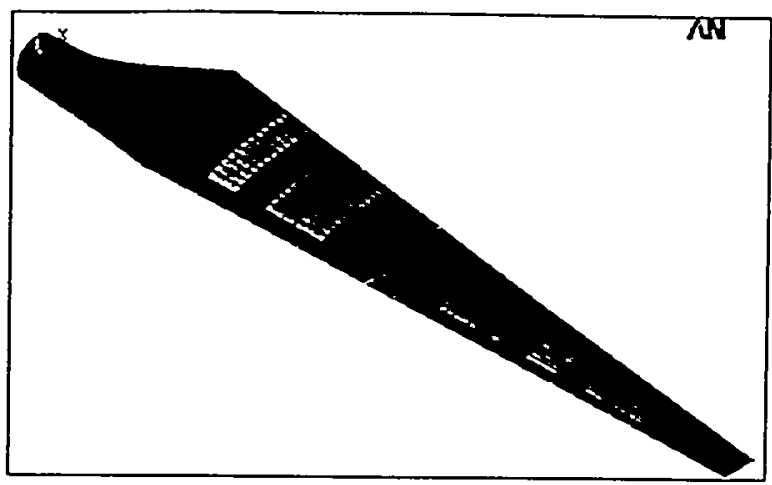

Figure 6. Blade finite element model with different materials and skin thicknesses highlighted.

\section{Manufacturing Process Research at Montana State University}

Montana State University has been performing research in fiberglass materials and fatigue for the wind program for many years. Much of this work culminated in the issuance of the DOE/MSU Composite Materials Fatigue Database (8). This database includes standard coupon tests with more than 4100 data points for at least 110 material systems. The report shows results expressed in stress- and strain-based Goodman Diagrams and includes guidance on how to incorporate such results into a blade design.

More recently, Sandia funded MSU to perform research in blade manufacturing. One of the main objectives was to explore Resin Transfer Molding (RTM) and Vacuum-Assisted RTM (VARTM) as manufacturing processes for utility-grade blades. This involved the study of parameters such as application rates, resin viscosity, injection criteria, fiber content, and fatigue life and how they apply to the specific requirements of a wind turbine.

Sandia purchased two resin injection machines to support the research in manufacturing as well as in materials and fatigue. The RTM System unit is a nofrills machine without process monitoring or controls, and has a high flow rate capacity - about $32 \mathrm{lb} /$ minute. The Venus Gusmer unit is a research-grade injection 
system with 2-12 lb./minute delivery rate. It has a very good monitoring system and incorporates data acquisition for rate of injection and process monitoring.

The practicality of using RTM in wind turbine blades was studied and reported in the technical note, "Resin Transfer Molding and Wind Turbine Construction." (9) This report compares the advantages and disadvantages of RTM to those of other manufacturing processes such as hand lay-up, compression molding, pultrusion, and filament winding. The major conclusion was that RTM can definitely add to the quality and repeatability of blade production.

A large study that discusses the results of testing RTM, VARTM, and hand lay-up structures was recently published in the report, "Evaluation of Hand Lay-up and Resin Transfer Molding in Composite Wind Turbine Blade Manufacturing" (10). The study compares and evaluates these processes according to fundamental criteria and mechanical performance for a variety of fabric reinforcements, lay-up schedules and turbine blade critical structures. The geometries investigated were flat plates, thin flanged $T$-stiffeners with skin intersections, thick flanged T-stiffeners (see Figs. 7 and 8 for representative pictures), I-beams, and sample root connection joints. Process variables explored were laminate thickness, fiber volume, cycle time, and porosity.

Some of the conclusions found were:

1. Resin transfer molding yields laminates of lower weight, higher fiber volume fraction, faster production capabilities, less dimensional variation, and little or no change in strength properties.

2. Compressive strengths showed significant improvements for RTM.

3. Vacuum assisted RTM exhibits the capability to reduce porosity well below that of hand lay-up.

Studies through analysis (FEM modeling) and testing have enhanced the understanding of non-linear buckling (11). Ways to prevent buckling in large unsupported panels becomes more important as we scale into the multi-MW turbines.

Additional work will continue to explore ways to lower safety factors in materials, design, and manufacturing that are required for certification (12).

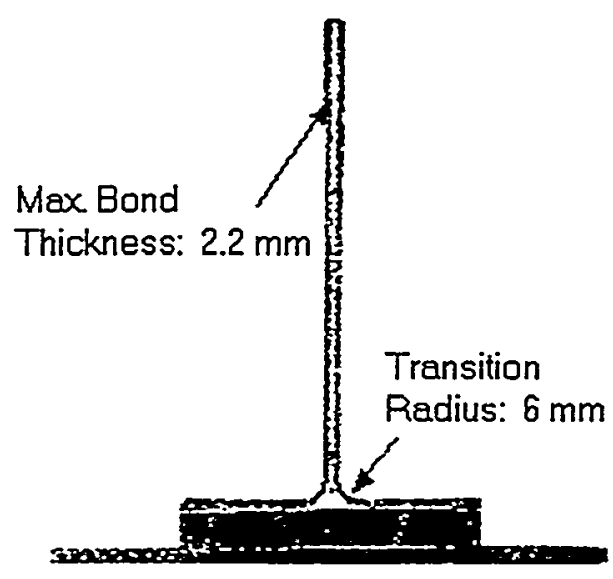

Figure 7. Hand lay-up thick flanged T-stiffener section.

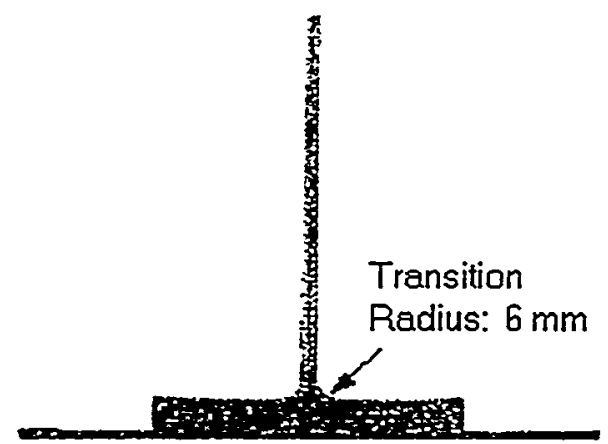

Figure 8. RTM thick flanged T-stiffener section.

\section{Headwaters}

In 1999 Headwaters Inc. was awarded a three-year EPSCoR (Experimental Program to Stimulate Competitive Research) contract entitled Building EPSCoR State National Laboratory Partnerships. The objective of the program is to make improvements to technologies that will also benefit a national laboratory. Headwaters is making an RTM manufacturing improvement to a composite blade substructure that will benefit Sandia Labs in the development of NuMAD.

More specifically, Headwaters is fabricating several Ibeams both by the hand lay-up and RTM processes. These beams will be tested (modal and statically) and modeled to compare the design properties with the actual properties. A score can then be given to each process grading how well each measure up to design specifications. 
The beams are eight feet long, with a depth of 8 in. $(0.20 \mathrm{~m})$ and width of 9 in. $(0.23 \mathrm{~m})$. The flange thickness is 0.5 in. $(12.7 \mathrm{~mm})$. Figure 9 shows an informal load test for the hand lay-up version of the I beam.

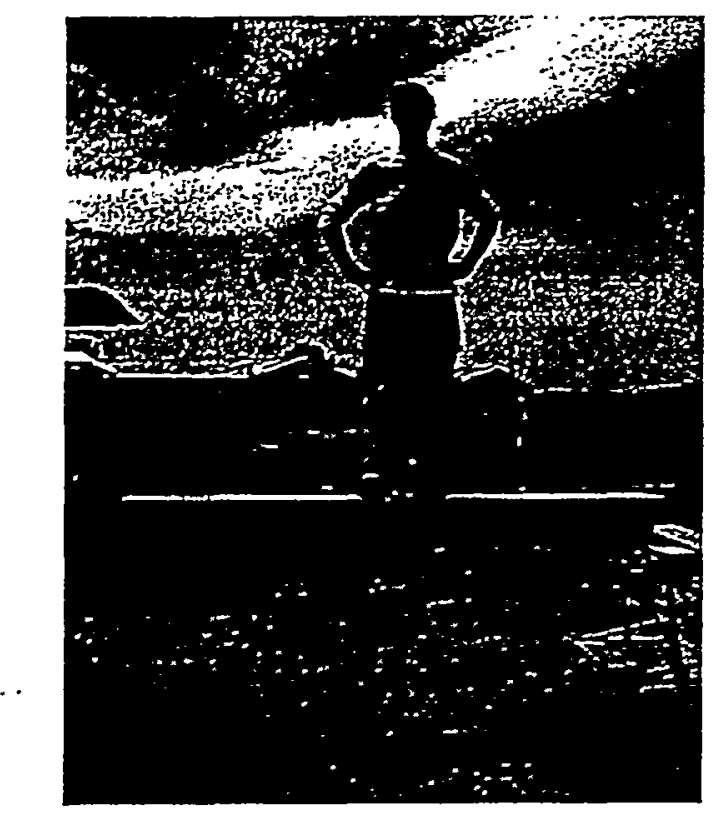

Figure 9. Headwaters I-beam (hand lay up)

\section{Adaptive Blades}

A related research task is the investigation of aeroelastic tailored blades. Such blades respond (by twist and/or bending) in ways that lower loads and enhance performance as the wind speed increases (13). It is currently planned to build a hybrid (carbon and e-glass) baseline blade with conventional fiber placement and fiber direction. A second blade (adaptively designed) will be fabricated to an aeroelastic-tailored set of specifications. This entails angling the fibers (typically 20 degrees from the main direction). The blades will be tested and a determination made on the cost and manufacturing benefits of aeroelastic tailoring.

\section{$\underline{\text { Summary }}$}

Work is ongoing in several areas pertaining to blade manufacturing. Industry contracts and applied research are helping to make more efficient blades, at lower costs and with improvements in manufacturing.

\section{References}

1. Poore, R.Z., Advanced Blade Manufacturing Project Final Report, SAND99-2017, Sandia National Laboratories, Albuquerque, 1999.

2. TPI Composites, ERS-100 Blade Manufacturing Draft Project Report, in preparation for Sandia National Laboratories, Albuquerque.

3. Hunsberger, R., et. al., Ultimate Static Load Testing on TPI Composites USW 56-100 LS-I and ERS-100 Rotor Blades, National Renewable Energy Laboratory, Golden, CO, 2000.

4. ANSYS, Inc., 201 Johnson Road, Houston, PA 15342-1300, (412) 746-3304.

5. Laird, D.L. and Ashwill, T.D., 1998, "Introduction to NuMAD: A Numerical Manufacturing and Design Tool," Proceedings, ASME/AIAA Wind Energy Symposium, pp. 354360.

6. Laird, D.L. and Ashwill, T.D., 1999, "NuMAD Update: A Numerical Manufacturing and Design Tool," Proceedings, ASME/AIAA Wind Energy Symposium, pp. 53-57.

7. Laird, D.L., 2001, "2001: A Numerical Manufacturing and Design Tool Odyssey," Proceedings, ASME/AIAA Wind Energy Symposium.

8. Mandell, J.F. and Samborsky, D.D., DOE/MSU Composite Material Fatigue Database: Test Methods, Materials, and Analysis, SAND973002, Sandia National Laboratories, Albuquerque, 1997.

9. Cairns, D. and Skramstad, J., Resin Transfer Molding and Wind Turbine Blade Construction, SAND99-3047, Technical Note, Sandia National Laboratories, 2000.

10. Cairns, D.S. and Scramstad, J.D., Evaluation of Hand Lay-up and Resin Transfer Molding in Composite Wind Turbine Blade Manufacturing, SAND2000-1425, Sandia National Laboratories, 2000.

11. Cairns, D. S., et.al., 2000, "Design Considerations for Buckling in Composite Wind Turbine Blades," Proceedings, ASME/AIAA Wind Energy Symposium.

12. Mandell, J. F., et.al., 1998, "Effects of Structural Details on Delamination and Fatigue Life of Fiberglass Laminates," Proceedings. ASME/AIAA Wind Energy Symposium.

13. Ong, C.H., Wang, J., and Tsai, S.W., 1999, "Design, Manufacture and Testing of a BendTwist D-spar," Proceedings, ASME/AIAA Wind Energy Symposium. 